\title{
Addressing antenatal sexually transmitted infections in a high HIV prevalence context: A qualitative study about partner notification in Botswana
}

Adriane Wynn, ${ }^{1,2}$ Corrina Moucheraud, ${ }^{3}$ Neo Moshashane, ${ }^{4}$ Ogechukwu Agatha Offorjebe, ${ }^{5}$ Doreen Ramogola-Masire, ${ }^{6}$ Jeffrey D. Klausner, ${ }^{5}$ Chelsea Morroni, ${ }^{4,6,7,8}$

\section{IUSTI WORLD \& EUROPEAN CONGRESS, 27-30 JUNE 2018, DUBLIN, IRELAND}

\section{Background}

Partner notification is essential to the management of sexually transmitted infections (STI). The process involves identifying sex partners, notifying about exposure, and providing counselling and treatment to:

- prevent reinfection of the index patient,

- reduce the community burden of infection, and

- prevent adverse health outcomes.

Partner notification and treatment rates are low.

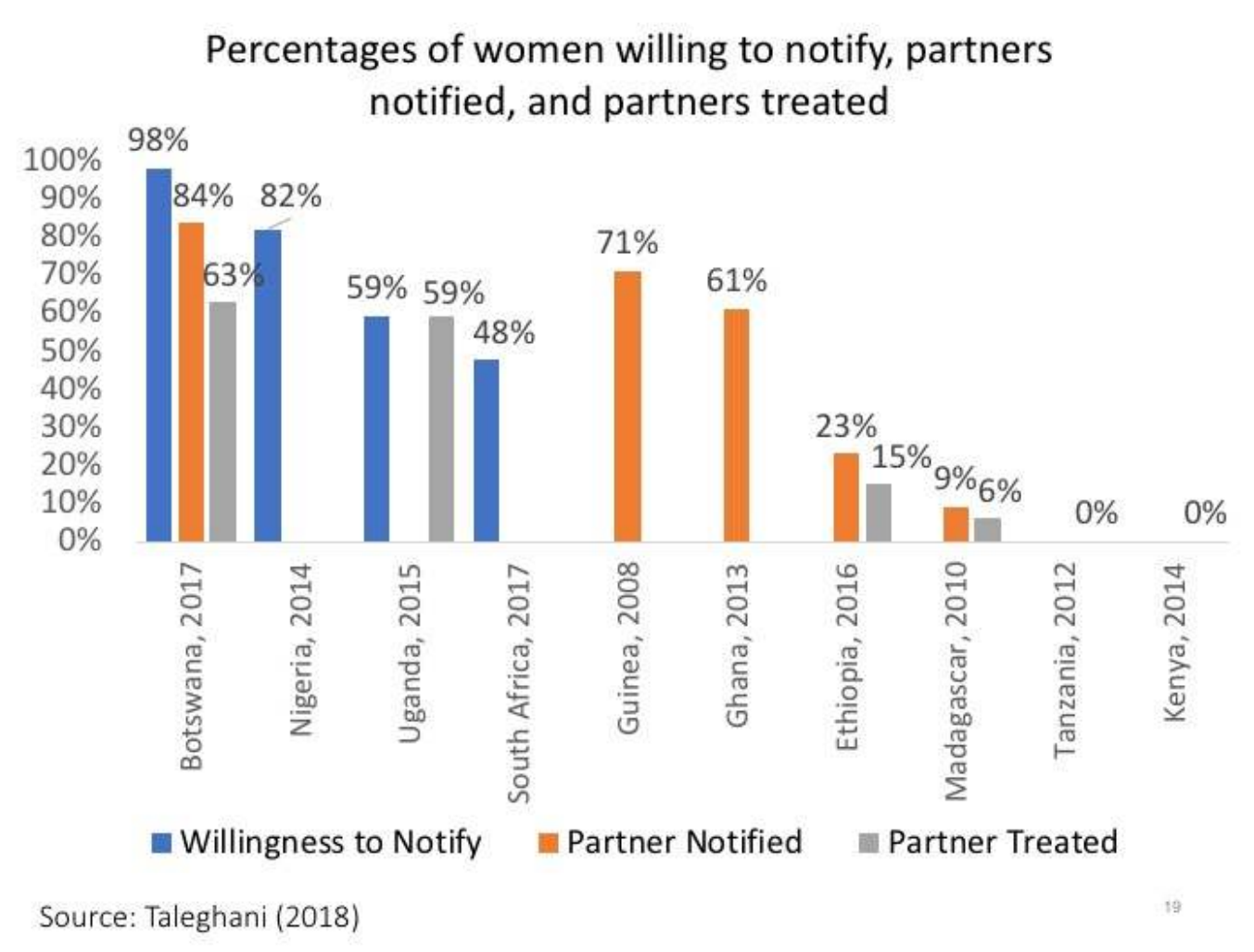

\section{Methods}

- In-depth interviews with 15 women diagnosed with curable STIs during antenatal care at Princess Marina Hospital in Gaborone, Botswana.

- Goal was to improve understanding of women's experiences and preferences related to partner notification and treatment for curable STIs.

- Interview transcripts assessed for frequently used codes, patterns, \& illustrative quotations.

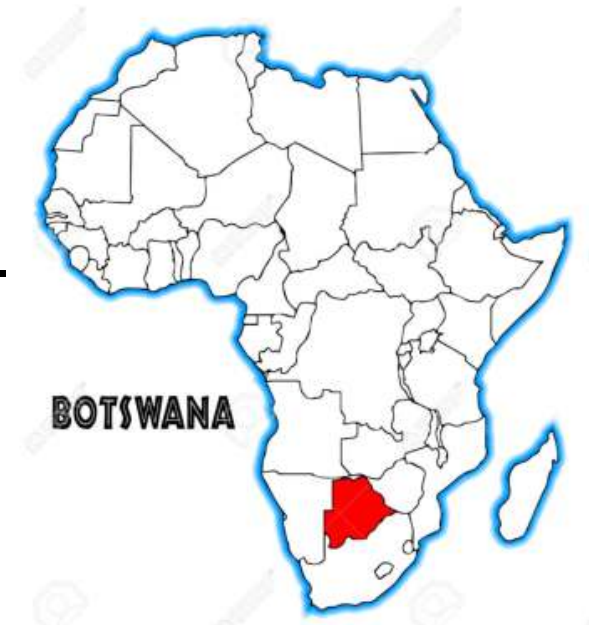

\section{Results}

- All current partners were notified, 2 women were no longer with their partners.

- Less than half of partners were treated and many received delayed treatment.

- Partner treatment barriers included:

-Work schedule

-No contact slip

-Women didn't have information

- Most women preferred to accompany partners to clinic (compared to him going alone or bringing him treatment).

- Experiences and preferences did not differ by HIV infection status.

\begin{tabular}{|l|l|}
\hline \multicolumn{1}{|c|}{ Theme } & \multicolumn{1}{c|}{ Quote } \\
\hline $\begin{array}{l}\text { Partners were } \\
\text { notified in person }\end{array}$ & $\begin{array}{l}\text { I didn't go around in circles, I got in and said, "I was in } \\
\text { [the clinic] and there were people testing for STDs so I } \\
\text { also tested, but came back positive...now you can read } \\
\text { these papers and see what kind of disease it is." }\end{array}$ \\
\hline $\begin{array}{l}\text { Few partners reacted } \\
\text { badly }\end{array}$ & $\begin{array}{l}\text { Now he is shouting at me... "What did you check for?" } \\
\text { saying "you like testing yourself for so many things!" } \\
\text {."So you think I sleep around with girls, am I sick?" } \\
\text { Right then we had sex again because he was shouting } \\
\text { right... I was calming him down. }\end{array}$ \\
\hline $\begin{array}{l}\text { Many women didn't } \\
\text { have enough } \\
\text { information for } \\
\text { partners }\end{array}$ & $\begin{array}{l}\text { "no when you get to the hospital, there's no evidence } \\
\text { that I can give you, when you get to the hospital you tell } \\
\text { them my partner was tested and she was found with } \\
\text { STl's." }\end{array}$ \\
\hline $\begin{array}{l}\text { Women preferred to } \\
\text { accompany partners } \\
\text { to clinic }\end{array}$ & $\begin{array}{l}\text { But if you give me the paper [contact slip] l'm going to } \\
\text { need to go with him because if I don't he won't do it [get } \\
\text { treated]. }\end{array}$ \\
\hline $\begin{array}{l}\text { Women did not } \\
\text { prefer expedited } \\
\text { partner therapy }\end{array}$ & $\begin{array}{l}\text { Ah, it wasn't going to be good. He was going to refuse... } \\
\text { He was going to ask himself what pills I was giving to } \\
\text { him that he hasn't been told about. }\end{array}$ \\
\hline
\end{tabular}

\section{Conclusion}

Pregnant women were willing to notify partners; however, there were barriers to partner treatment. Efforts are needed to increase STI knowledge and overcome logistical barriers to ensure prompt partner treatment, and reduce rates of re-infection during pregnancy and subsequent adverse health outcomes.

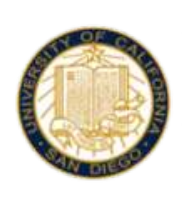
UCSanDiego SCHOOL of MEDICINE

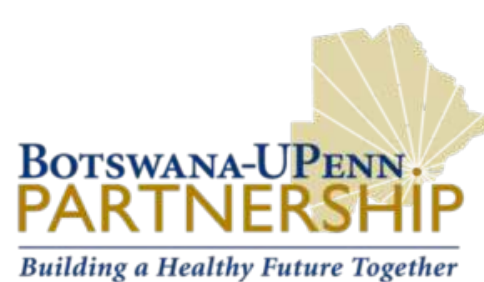

Building a Healthy Future Together
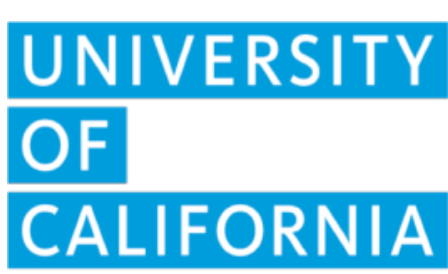

Team Klausner

Saving Lives

Affiliations: 1. School of Medicine, UCSD; 2. UC Global Health Institute; 3. Fielding School of Public Health, UCLA; 4. Botswana-UPenn Partnership, 5. Geffen School of Medicine, UCLA; 6. University of Botswana; 7. EGA Institute for Women's Health and Institute for Global Health, UCL, 8. Wits Reproductive Health and HIV Institute, University of Witwatersrand.

Acknowledgements: Fogarty International Center (2D43TW009343-06); UCSD (T32DA023356); TKSL. 